\title{
Full-Fledged Use of Semi-Basement Space by Building Seismic-Resistance, Energy-Efficiency, Microclimate and Preventing Influences of Thermal Bridges and Mold Growth
}

\author{
Erkin Boronbaev ${ }^{1,}$, , Berikbay Unaspekov ${ }^{2}$, Aigul Abdyldaeva ${ }^{1}$, Elmira Tohlukova ${ }^{3}$, \\ Kamoliddin Holmatov ${ }^{1}$, Nurbubu Zhyrgalbaeva ${ }^{1}$ \\ ${ }^{1}$ Department of Heat-Gas Supply and Ventilation, Kyrgyz State University of Constructions, Transportation and Architecture \\ named after N. Isanov, 720020, 34 b, Maldybaev str., Bishkek, Kyrgyzstan \\ ${ }^{2}$ Department of Engineering Systems and Networks, Kazakh National Technical University named after K.I. Satpayev, 050013, 22, \\ Satbaev str., Almaty, Kazakhstan \\ ${ }^{3}$ Professional Center for Construction and Civil Engineering, 13 rue Denis Papin BP 95, 78190, Trappes, France
}

Received August 31, 2021; Revised October 25, 2021; Accepted November 11, 2021

\section{Cite This Paper in the following Citation Styles}

(a): [1] Erkin Boronbaev, Berikbay Unaspekov, Aigul Abdyldaeva, Elmira Tohlukova, Kamoliddin Holmatov, Nurbubu Zhyrgalbaeva, "Full-Fledged Use of Semi-Basement Space by Building Seismic-Resistance, Energy-Efficiency, Microclimate and Preventing Influences of Thermal Bridges and Mold Growth," Civil Engineering and Architecture, Vol. 10, No. 1, pp. 131 - 143, 2022. DOI: 10.13189/cea.2022.100112.

(b): Erkin Boronbaev, Berikbay Unaspekov, Aigul Abdyldaeva, Elmira Tohlukova, Kamoliddin Holmatov, Nurbubu Zhyrgalbaeva (2022). Full-Fledged Use of Semi-Basement Space by Building Seismic-Resistance, Energy-Efficiency, Microclimate and Preventing Influences of Thermal Bridges and Mold Growth. Civil Engineering and Architecture, 10(1), 131 - 143. DOI: 10.13189/cea.2022.100112.

Copyright $\odot 2022$ by authors, all rights reserved. Authors agree that this article remains permanently open access under the terms of the Creative Commons Attribution License 4.0 International License

\begin{abstract}
The known theory and experience of energy-saving architecture allow solving the article's task and ensuring sufficient insolation, passive solar heating, and occupants contact with nature through semi-basement windows. The goal is a full-fledged use of the semi-basement space achieved for seismically active regions with a moderate, cold, and hot climate by ensuring the normative seismic-resistance, energy-efficiency, and microclimate of the building and preventing influence of thermal bridges and mold growth. The set of recommendations also covers the provision of the required sanitary-hygienic conditions in the semi-basement rooms. The multidisciplinary problem is solved by integrating the methodologies of various fields of science. By means of numerical investigations, it established that the soil adjacent to the semi-basement foundation wall increases the thermal mass and building envelope heat-protection capacity. The isotherms and the intensity of heat fluxes made it possible to eliminate the effect of thermal bridges
\end{abstract}

that interact with the soil and outside air. The expedient thickness and width of the additional layer of thermal insulation of thermal bridge zones in excess of the normative layer of the enclosure's thermal insulation were established. The graphical dependence of the wall's inner corner temperature from this width allows selecting the microclimate level. A multilateral contribution to building improvement is derived from a single-family home example: comfortable microclimate conditions have been created in the semi-basement for placing main rooms there; energy savings for heating this space is $16-20 \%$; saving of monolithic frame and foundation concrete is $10-12 \%$ ensuring the higher than normative building seismic-resistance.

Keywords Semi-Basement Rooms, Seismic-Resistance, Energy-Efficiency, Microclimate, External Enclosures, Thermal Bridges, Isotherms, Mold Growth 


\section{Introduction}

In all regions with cold, hot climates and high seismicity, the building enclosure constructions must have reliable thermal protection and high strength. The basement and semi-basement spaces of such buildings are often created using monolithic concrete foundation structures. In practice, such basement spaces are used only as ancillary rooms due to the low heat protection capabilities of the external enclosures. Accordingly, the year-round thermal microclimate in these rooms does not meet the normative requirements for the main premises of the building.

The authors found that heating the basement rooms is inadvisable, on the one hand, because of the high consumption of thermal energy, and on the other hand, it is difficult to achieve the standard microclimate parameters due to low temperatures on the inner surfaces of the enclosures. This state of affairs is because there are no scientifically substantiated solutions for these problems.

In work [1] it is noted that improving the energy efficiency of buildings can be achieved by multifactorial consideration and creation of its energy saving architecture. The year-round thermal "behavior" of the building is considered depending on the daily and long-term interaction of the building with the dynamic renewable energy of the environment and incoming solar radiation. At the same time, the choice of an appropriate location, volume, shape, size, orientation, and level of thermal protection of both the building as a whole and its individual rooms and enclosures is achieved.

Decisions should be made on the basis of a multidisciplinary approach, an imitative mathematical model of the building [1] and the results of field studies $[2,3]$ carried out in the existing building by means of non-contact hourly and daily temperature measurements on the internal and external surfaces of external walls and windows. In particular, the author [1] notes the energy advantage of joining individual external enclosures and premises of the building to the foundation soil.

It has been established [4] that the level of energy efficiency and the internal microclimate of a building significantly increase with the implementation of scientifically based measures to reduce the negative effect of thermal bridges in external enclosures. In a residential building, it is beneficial to use the semi-basement space to accommodate the main rooms when creating regulatory parameters of the thermal inner microclimate.

The authors of work [5] came to a similar conclusion that the use of the underground space of hospitals has significant advantages. Accommodation of rooms in the basement for patients and staff allows for the reduction of land area for the construction of the building.-It is noted that a stable temperature and a low level of external noise input are observed inside of such rooms.

The author of [1] found that the greater the thermal mass of the external and internal enclosures of the room, the lower the daily and seasonal parameter fluctuations of the internal microclimate. In an unheated basement, there are [6] also significant heat losses of from pipelines of water heating and hot water supply systems. Special studies have shown that a higher thermal mass of the enclosures allows the reduction of heat and cold consumption [7] when heating and cooling a building. These scientific conclusions serve as the basis for the practical use of the semi-basement.

Its concrete walls also serve as a seismic-resistant foundation for the building. Some parts of these walls are adjacent to the surrounding ground, which greatly enhances the overall effect of the thermal mass of the premises. It is fairly noted [7] that in the "underground" space people experience an uncomfortable feeling. However, using techniques of energy-saving architecture [1], these and other obstacles can be solved. In particular, in semi-basement rooms, a sufficient level of insolation, passive solar heating, and daylight is easily ensured, as well as a pleasant visual contact of people with the natural environment.

The article [8] presents the results of energy retrofitting of a typical residential building in different climatic zones in order to reduce the level of energy consumption and discomfort in the premises. For these purposes, the building's thermal protection has been improved by means of feasible and optimized modernization. Optimization of thermal behavior and energy efficiency of buildings has been achieved for each climatic zone. The overall potential for improved thermal comfort and energy savings is determined relative to reference conditions.

It should be noted that reducing building energy consumption due to energy-saving architecture [1], managing buildings thermal comfort [9], and increasing their energy efficiency [4] can reduce greenhouse gas emissions into the atmosphere in order to slow down the rate of planetary climate change. The solution to this problem is relevant and important for individual low-rise residential buildings. This is also due to the fact that the number of such buildings is large, since most of the population lives in similar houses, both in the two countries under consideration, and in many other countries with similar seismic, climatic and other conditions.

Numerous such buildings in mountainous areas are in dire need of improving their energy efficiency, indoor microclimate and seismic resistance. The solution to this multidisciplinary problem is further complicated by the fact that imperfect structures of external enclosures cause a violation of sanitary-hygienic conditions in buildings due to the appearance of mold on internal surfaces covered with hygroscopic materials.

In articles $[1,4,10]$, various practical recommendations are proposed to prevent the growth of mold caused by the 
negative effect of architectural and structural thermal bridges. The work [4] for the first time provides a theoretically substantiated definition of thermal bridges and their classification that is presented as architectural, structural, and exploitative thermal bridges.

The authors of [11] considered the calculation methods of determining the period of appearance or absence of mold and condensation of air moisture on the inner surface of the enclosures. The features of the specific rooms, enclosures, and outdoor climatic conditions are taken into account.

The authors of work [12] have developed practical recommendations for improving the energy efficiency of individual external enclosures. In article [13], additional thermal insulation of the zone of thermal bridges in the brick external walls of individual residential buildings is proposed. Such a constructive solution is recommended to be used [13] for buildings in 28 settlements of Kyrgyzstan and 21 in Tajikistan, covering a wide range of climate and seismicity indicators in construction areas: Degree-days from $1282 \mathrm{C}^{\circ}$. day of the normative heating period (Yavan station, Tajikistan) to $7834 \mathrm{C}^{\circ}$. day (Taragai station, Kyrgyzstan) with seismicity of the area of 7, 8, and 9 points on the MSK-64 scale.

\section{Materials and Methods}

This article discusses the multidisciplinary task of ensuring the normative levels of energy efficiency and microclimate of the semi-basement of a seismic-resistant residential building while preventing the effect of thermal bridges in external enclosures and mold growth on their internal surfaces. The materials of the building as an object of study are ordinary concrete, reinforced concrete, cement-sand mortar, burnt brick, and typical materials for waterproofing and thermal insulation.

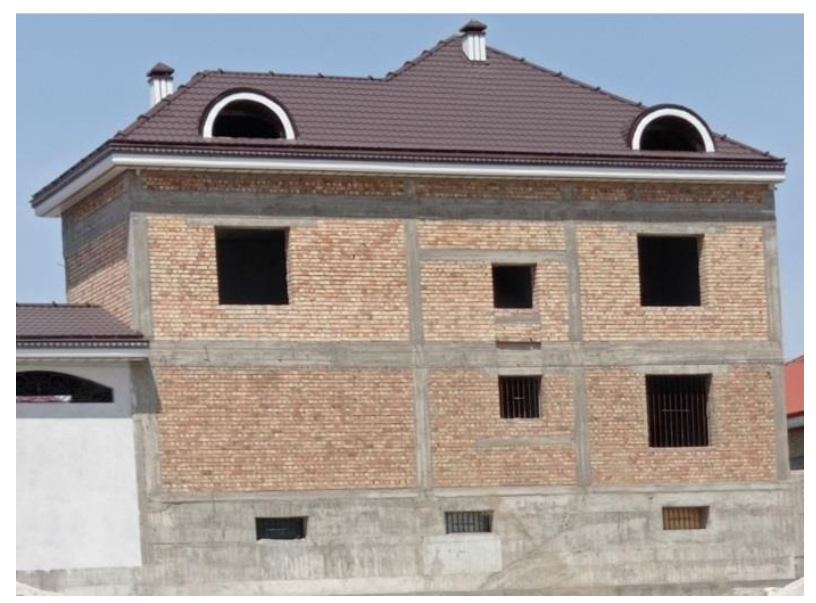

Figure 1. The exterior of a seismic-resistant brick residential building (2, Bakhoriston St., Khujand, Tajikistan)

Preferably the case of the construction of a building, where a seismic-resistant reinforced concrete frame is constructed first, followed by masonry brick infill, which allows free deformation of the frame during an earthquake. In practice, there is a second, less technologically advanced construction method of a building (Figure 1), where the erected brick walls are used for the sequential pouring of a monolithic seismic-resistant reinforced concrete frame.

In this case, the desired free deformation of the monolithic reinforced concrete frame is limited due to the rigid connection of the brick walls to it. Considering these circumstances, the article adopted for research the more acceptable first case for a building's construction, with the main geometric indicators, including dimensions $12 \mathrm{~m} \mathrm{x} 8$ $\mathrm{m}$ in the plan, of the example of a building in Figure 1.

The building has a brick-filled monolithic reinforced concrete frame and a concrete foundation serving as the external wall of the semi-basement rooms. For consideration, data taken were the seismicity of the construction area at 7, 8 and 9 points on the MSK 64 scale, various climatic conditions, 4 types of soil with standard structural properties and moisture content at a low groundwater level.

Numerical investigation methods are taken as the basis for studying the tasks with the usage of software packages. Software package «LiraSAPR 2016» was used to calculate the seismic resistance of the building. The software package «ArchiCAD 23» allowed providing the required parameters of a comfortable microclimate in the semi-basement rooms.

Calculations and graphical representations of two-dimensional temperature distribution as isotherms on the cross-sections of enclosures and building frame elements have been carried out. The temperature values on the interior surfaces of the enclosures, especially on the corner zones, formed the basis for the development of practical recommendations for ensuring the normative microclimate level.

Practical measures are proposed to prevent the negative thermal effect of thermal bridges, which causes low temperatures and mold growth on the inner surfaces of enclosures. Figure 2 shows a photo of mold on the inner surface of the corner floor area of semi-basement rooms with concrete external walls.

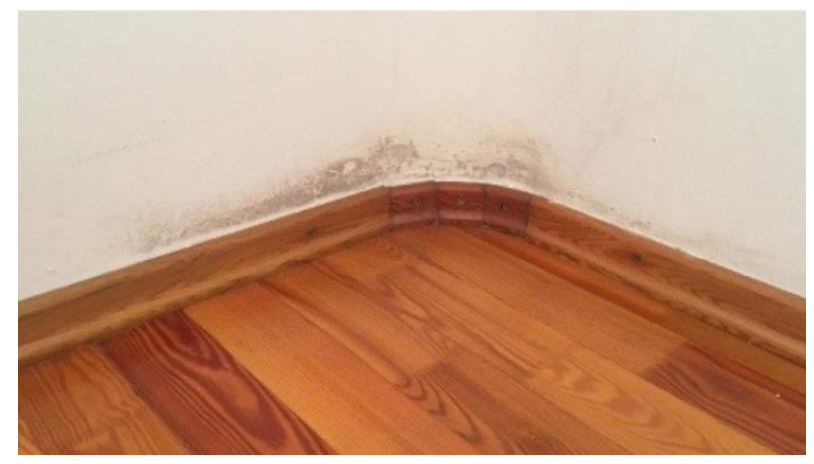

Figure 2. Photo of mold on the inner surfaces of the corner zone of the semi-basement floor

As can be seen, mold growth is observed even on 
surfaces remote from the corner, since in this building the concrete walls had insufficient thermal protection. The consumption of heat energy for space heating the rooms was calculated using the «VALTEC» calculation program. It allows finding the local values of heat losses through the elements of external enclosures. Based on such calculations, the level of energy efficiency of the developed design solutions was determined.

It is known that at an air temperature in a room of about $20{ }^{\circ} \mathrm{C}$, the heat losses of the human body occur by convection, radiation, evaporation of moisture and thermal conductivity. When a person is in a calm state, about half of the total heat losses are losses by radiation depending mainly on the average temperature of surfaces facing the interior. Accordingly, in order to improve the conditions of the thermal microclimate of the room, it is efficient to increase this temperature. For this reason, the difference $\Delta t$ between the temperature on the external wall's inner surfaces and the air temperature in the room must be lower than $4{ }^{\circ} \mathrm{C}$ by norms SNiP KR 23-01-2013 "Thermal protection of buildings" of Kyrgyzstan (The authors E. Boronbaev and A. Abdyldaeva are members of the development team of this national code).

On the mentioned fundamental scientific and practical basis, it has been established that one of the main tasks of this article is to increase the temperatures on the inner surfaces of the external enclosures of the semi-basement space

\section{Results}

\subsection{Results on Seismic Resistance}

The stress-strain state of the building under the simultaneous action of static and dynamic loads is considered.

The calculation was carried out by the finite element method using the "LiraSAPR 2016" software package. The calculation takes into account the masses of the building elements and live loads as well as the horizontal and vertical ground pressure on the basement walls. For dynamic loads, seismic forces $S_{\mathrm{ik}}$ are taken into account. The seismicity of the construction area is 9 points on the MSK-64 scale with the sand soil category. A general view of the design model of the building is shown in Figure 3.

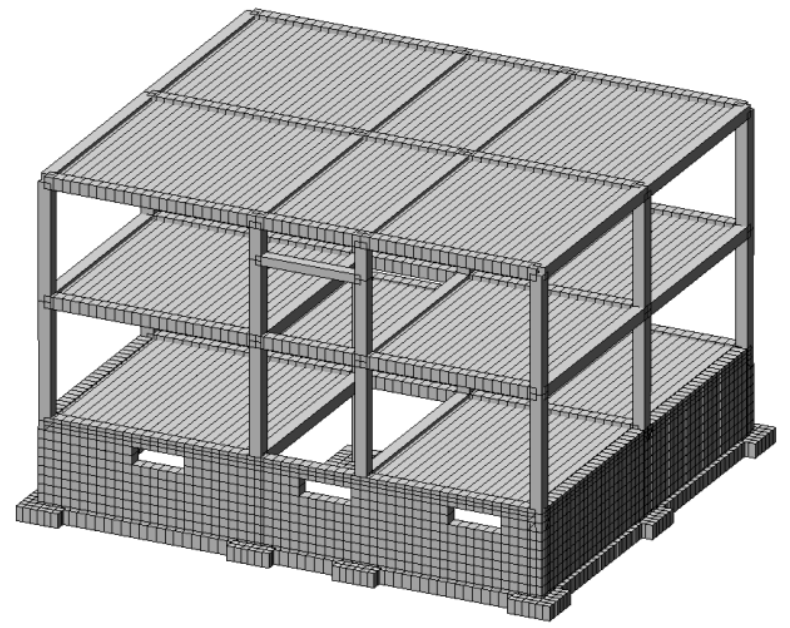

Figure 3. The design model of the residential building shown in Figure 1

For the wall, concrete of class B15 was adopted with an elastic modulus of $\mathrm{E}=2.350 .000 \mathrm{t} / \mathrm{m}^{2}$, and for columns and crossbars, concrete of class B 25 with $\mathrm{E}=3.060 .000$ $\mathrm{t} / \mathrm{m}^{2}$. The loads from self-supporting walls in the form of brickwork with a width of $380 \mathrm{~mm}$ are taken into account. As option I the existing building (according to Figure 1) is considered with a concrete wall thickness of $400 \mathrm{~mm}$ and a cross-section size of columns and crossbars of $380 \mathrm{~mm}$ x $380 \mathrm{~mm}$. The calculation of the seismic resistance of this option I showed that these geometrical indicators are much higher than the required ones. This leads not only to overconsumption of concrete, but also enhances the negative thermal effect of thermal bridges. On the basis of calculations of the seismic resistance of the building, option II was proposed for further consideration. The recommended thickness of the concrete wall is $360 \mathrm{~mm}$ and the cross-sectional dimensions of the columns and girders of $340 \mathrm{~mm} \times 340 \mathrm{~mm}$. For this option, Figure 4 shows the results of calculating the deformations $\delta_{\mathrm{x}}$, and $\delta_{\mathrm{y}}$ in the $\mathrm{X}$ and $\mathrm{Y}$ directions.

It can be seen that the lower zones of the wall have a slight displacement due to the pressure of the mass of the adjacent soil. The estimated maximum displacement of the top points of the concrete wall in the $\mathrm{X}$-direction is about $0.74 \mathrm{~mm}$ and in the $\mathrm{Y}$-direction is about $0.96 \mathrm{~mm}$. 

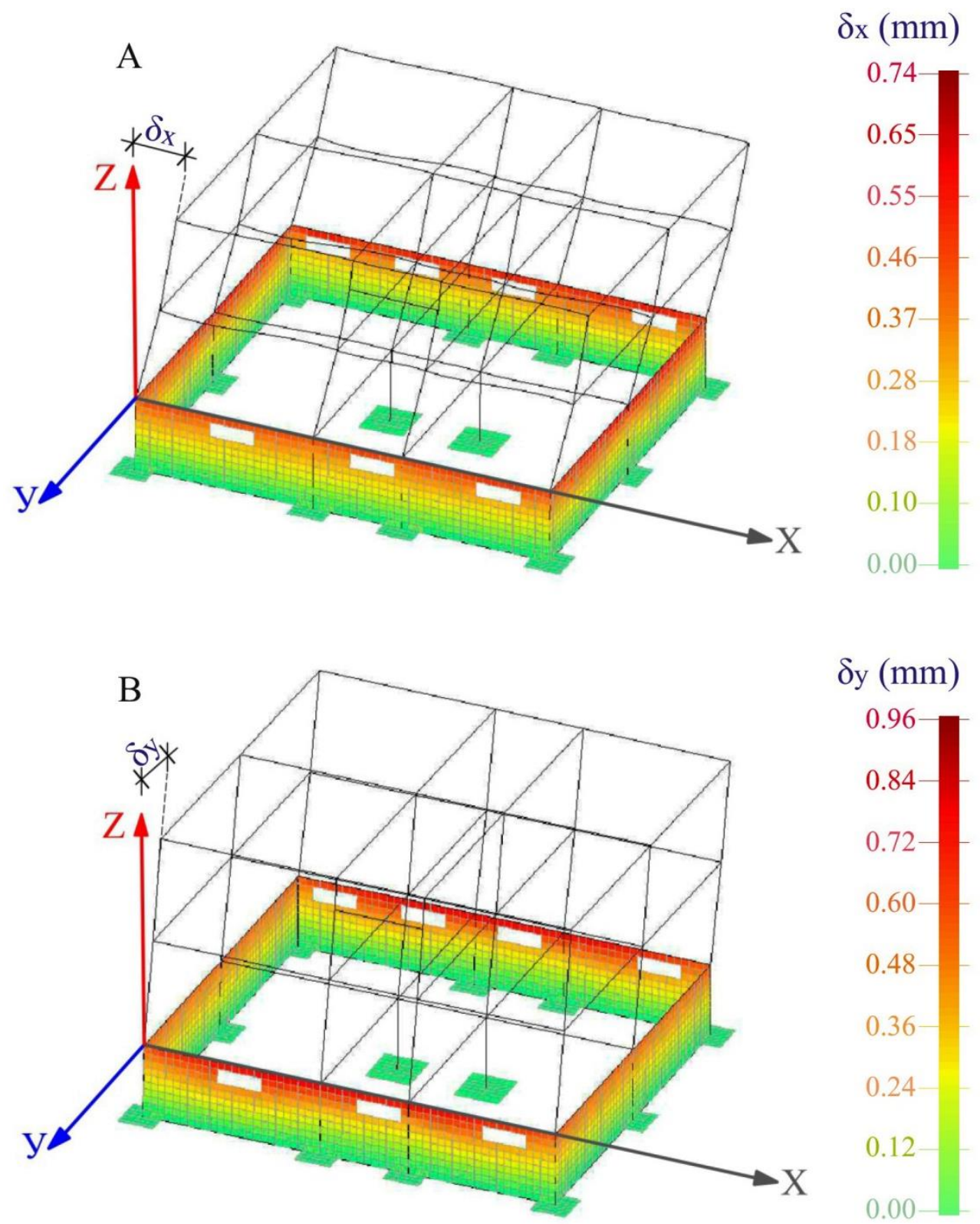

$\delta \mathrm{y}(\mathrm{mm})$

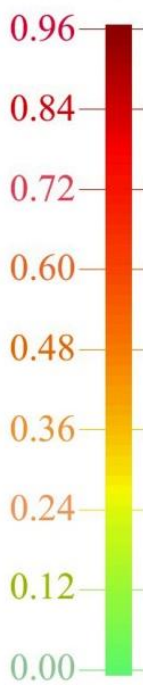

Figure 4. Displacements of concrete semi-basement walls and a reinforced concrete building frame by static and seismic loads: (A) displacements along the "X" axis; (B) displacements along the "Y" axis.

Table 1. The calculations results of seismic resistance of a concrete wall and frame of the existing and proposed building

\begin{tabular}{|c|c|c|c|c|c|c|}
\hline \multirow{2}{*}{\multicolumn{3}{|c|}{ Indicators }} & \multicolumn{4}{|c|}{ Displacements, $\delta_{x}$ and $\delta_{y}, \mathbf{m m}$} \\
\hline & & & \multirow{2}{*}{\multicolumn{2}{|c|}{$\begin{array}{l}\text { Of the semi-basement walls } \\
\text { top point }\end{array}$}} & \multirow{2}{*}{\multicolumn{2}{|c|}{$\begin{array}{l}\text { Of the reinforced concrete frame } \\
\text { top point }\end{array}$}} \\
\hline \multirow{2}{*}{ Options } & \multirow{2}{*}{$\begin{array}{l}\text { Wall thickness, } \\
\text { mm }\end{array}$} & \multirow{2}{*}{$\begin{array}{c}\text { Dimensions of frame } \\
\text { elements, } \mathbf{m m}\end{array}$} & & & & \\
\hline & & & $\delta_{\mathrm{x}}$ & $\delta_{\mathrm{y}}$ & $\delta_{\mathrm{x}}$ & $\delta \delta_{y}$ \\
\hline I & 0,69 & 0,82 & 0,69 & 0,82 & $23\left(f_{u}=33\right)$ & $27\left(f_{u}=33\right)$ \\
\hline II & 0,74 & 0,96 & 0,74 & 0,96 & $27\left(f_{u}=33\right)$ & $30\left(f_{u}=33\right)$ \\
\hline
\end{tabular}

The largest span of internal crossbars is $\mathrm{L}=6 \mathrm{~m}$. According to code SP 20.13330.2011 [14], the vertical deflection of such crossbars under the influence of constant and long-term loads should not exceed the limit value $f_{u}=(1 / 200) \cdot L=0.03 \mathrm{~m}$. Corresponding calculations have established that with an assumed cross-section of $340 \mathrm{~mm} \times 340 \mathrm{~mm}$ of these crossbars, their vertical deflection, firstly, under the influence of total static loads is only $16.7 \mathrm{~mm}$; secondly, under the influence of the reference vertical seismic loads $S_{\mathrm{ik}}$, determined according 
to code SP 14.13330.2018 [15], is - $5.59 \mathrm{~mm}$. Therefore, the accepted contraction of the crossbars satisfies the second limit state (serviceability) condition.

\subsection{Results on Energy Efficiency and Microclimate}

To solve the provided research problem, the two-dimensional temperature fields of the cross-sections of the elements of external enclosures and the adjacent isotropic soil mass were considered using the «ArchiCAD 23» software package. The isotherms and the intensity of heat fluxes results made it possible to eliminate the effect of thermal bridges that interact with the soil and outside air.

A construction site was accepted for the Khujand city (Tajikistan) with a seismicity of 9 points, with dry sand (with a thermal conductivity coefficient $\lambda=0.06 \mathrm{~W} / \mathrm{m} \cdot \mathrm{K}$ ), with a groundwater level below the base of the foundation, the design temperature of the outside air $-13.3^{\circ} \mathrm{C}$.

In local practice, many low-rise buildings are used without thermal insulation on the external walls. Sometimes the layers of thermal insulation are taken with a thickness that is much less than the required one, and even without calculations. Often, basements are not thermal insulated at all. This is also due to the local circumstance where technological experience and materials that are suitable for concrete external walls are not available, especially in those parts that are adjacent to the base soil. It is necessary to substantiate the expediency of placing the main premises of a residential building on a semi-basement at reference internal air temperature for a cold period of $20^{\circ} \mathrm{C}$.

The structural features of the external walls of the existing building (see Figure 1) are shown in Figure 5A.
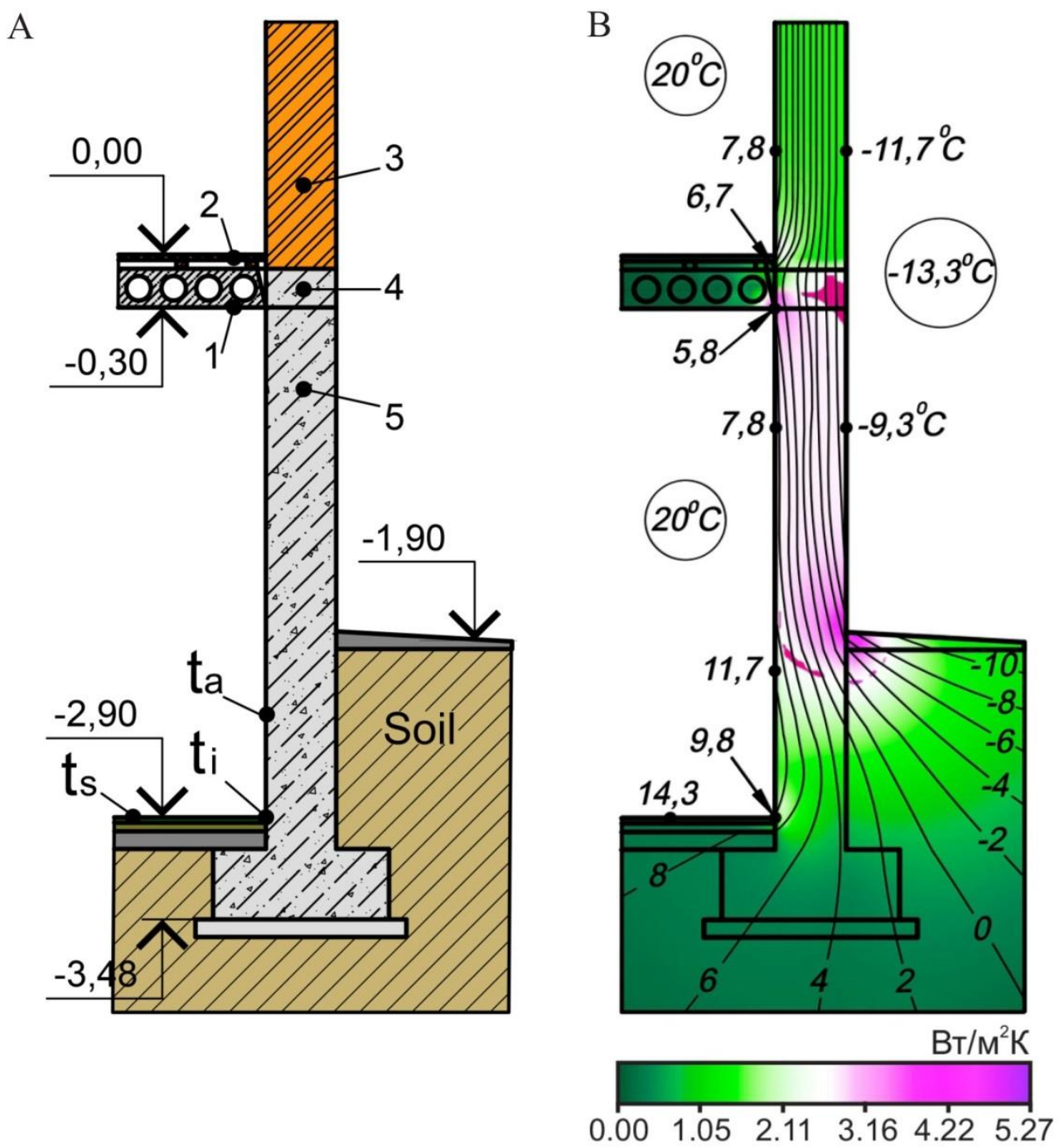

Temperatures on main surfaces: $\mathrm{t}_{\mathrm{s}}-$ of a floor; $\mathrm{t}_{\mathrm{a}}-$ of a concrete wall; $\mathrm{t}_{\mathrm{i}}-$ of a floor corner; 1 - floor slab; 2 - floor structure; 3 - brick wall; 4 anti-seismic belt; 5 - concrete wall

Figure 5. Cross-section of the existing semi-basement wall without thermal insulation: (A) structure of the foundation wall and brick wall; (B) isotherms and heat flux density 
As seen in Figure 5B, the temperature on the inner surfaces of the wall in the zone of its abutment to the warmer soil $\mathrm{t}_{\mathrm{a}}=11.7^{\circ} \mathrm{C}$ and the floor $\mathrm{t}_{\mathrm{s}}=14.3^{\circ} \mathrm{C}$ are higher than the temperature of $7.8^{\circ} \mathrm{C}$ in the zone of abutment to the cold outside air. For the same reason, the temperature at the corner of the floor $t_{i}=9.8^{\circ} \mathrm{C}$ is relatively higher than the temperature at the corner at the ceiling of $5.8^{\circ} \mathrm{C}$ and at the floor of the upper floor $6.7^{\circ} \mathrm{C}$. The latter values of the angular temperatures are lower than the temperatures on the main surface of the brick and concrete wall. This is due to the negative effect of architectural and structural thermal bridges [4] in the junction area of the external enclosures.

The above temperature conditions show that even when the rooms are heated while maintaining them at $20^{\circ} \mathrm{C}$, not only are the required microclimate conditions not provided, but also the condensation of air moisture is not prevented.

For this reason, residents use the basement space only as ancillary space.

A

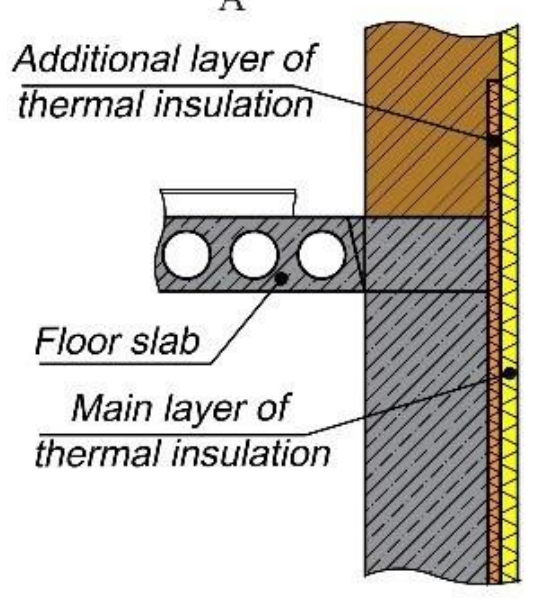

For the climatic conditions of Khujand for an external brick wall with a thickness of $380 \mathrm{~mm}$, a normative thickness of thermal insulation of a mineral wool slab of $50 \mathrm{~mm}$ with a thermal conductivity coefficient $\lambda=0.06$ $\mathrm{W} / \mathrm{m} \cdot \mathrm{K}$ is required. This thickness is determined in accordance with the current regulatory document SNiP KR 23-01-2013.

The authors of works $[10,13]$ proposed to eliminate the indicated negative effect of the thermal bridge using an additional layer of thermal insulation of the zone of its influence. Figure 6A shows the proposed constructive solution for the junction zone of the inter-floor overlap with the concrete wall of the basement and the brick wall of the upper floor.

When the reference main layer of thermal insulation is $50 \mathrm{~mm}$ thick and the additional layer is $40 \mathrm{~mm}$ thick, the temperature on the corner is $17.2^{\circ} \mathrm{C}$ (Figure 6B). The difference $\Delta \mathrm{t}$ between this temperature and the air temperature in the room $\left(20^{\circ} \mathrm{C}\right)$ is $2.8^{\circ} \mathrm{C}$, which is lower than $4^{\circ} \mathrm{C}$ allowable by norms SNiP KR 23-01-2013.

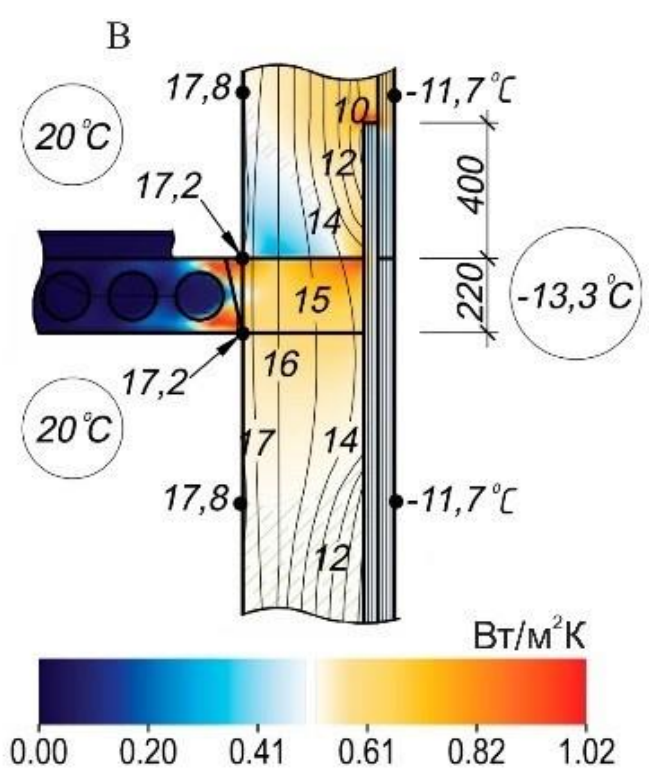

Figure 6. Constructive solution of the coupling inter-floor with the external concrete wall: (A) cross-section; (B) isotherms and heat flux density 

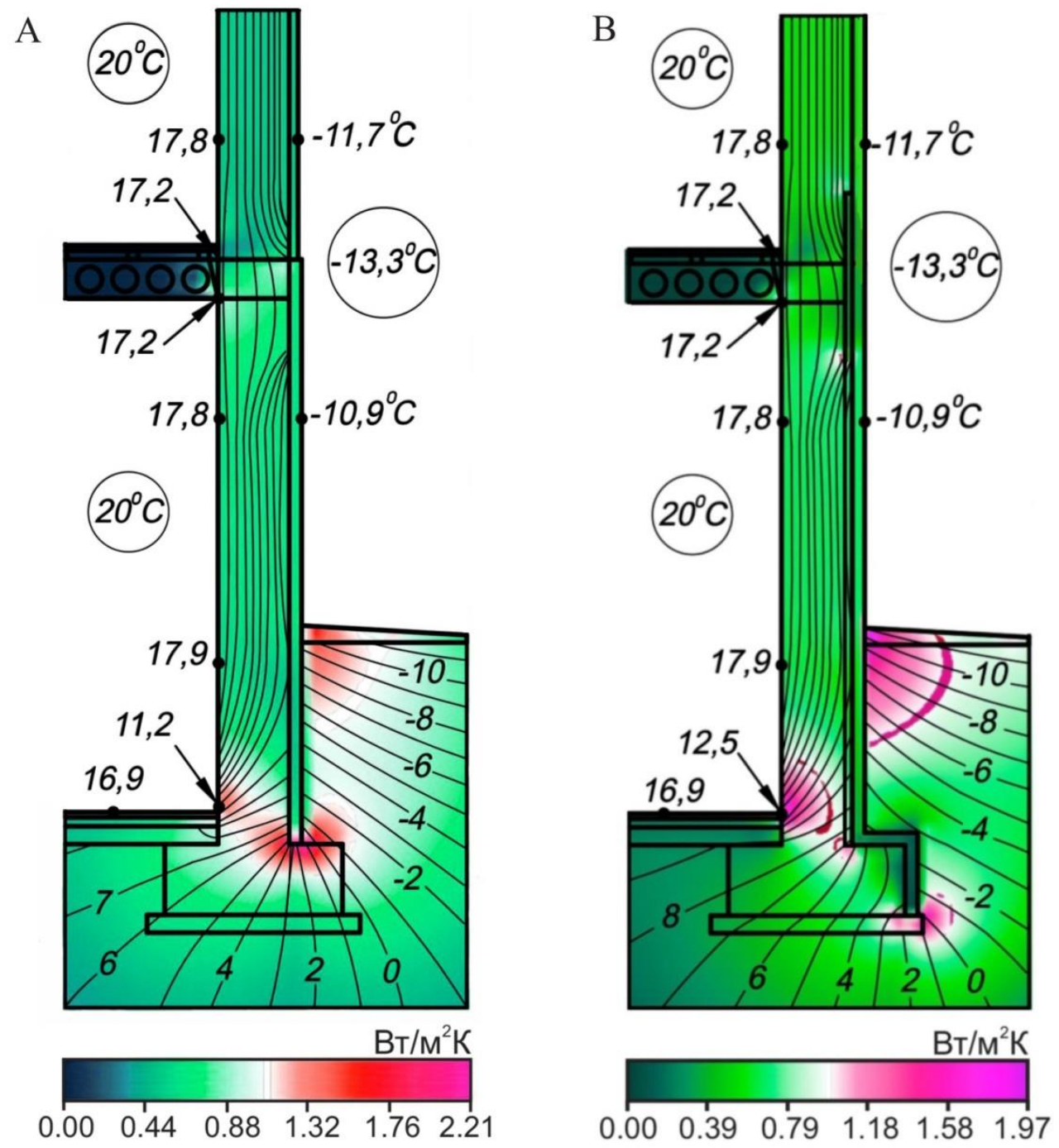

Figure 7. Isotherms and heat flux densities: (A) before thermal insulation; (B) after thermal insulation

As seen in Figure 7A, with the specified main and additional layer of thermal insulation of the external wall, the temperature at the corner of the semi-basement floor is $11.2^{\circ} \mathrm{C}$

Therefore, the difference $\Delta \mathrm{t}$ between this temperature and the air temperature in the room is $8.8^{\circ} \mathrm{C}$, which is higher than the allowable $4^{\circ} \mathrm{C}$. Based on the nature of the isotherms and higher local heat fluxes in the corner zones (see Figure 7A), the authors concluded that thermal insulation of the basement base is required. Figure 7B shows the thermal insulation as a continuation of its 50 $\mathrm{mm}$ thick base layer. At the same time, the temperature at the corner of the floor became $12.5^{\circ} \mathrm{C}$. The specified difference $\Delta \mathrm{t}$ decreased to $7.5^{\circ} \mathrm{C}$, but it is still more than the allowable $4.0^{\circ} \mathrm{C}$. Accordingly, second additional thermal insulation of the thermal bridge zone of the foundation base is required.

Figure 8A and Figure 8B show structural elements with stronger thermal insulation of the thermal bridge zones.

Based on consideration of the features of isotherms and local heat flux (see Figure 8C), firstly, a second layer of additional thermal insulation made of mineral wool slabs $40 \mathrm{~mm}$ thick, and secondly, with its upper width $\mathrm{h}=400$ $\mathrm{mm}$, were installed.

As seen in Figure $8 \mathrm{C}$, temperatures $17.2^{\circ} \mathrm{C}$ (and $17.8^{\circ} \mathrm{C}$ ) on the corners of the concrete wall at the ceiling and floor are significantly higher than the normative permissible $16^{\circ} \mathrm{C}$. It also seen that the temperatures on the main surface of the concrete wall $\left(17.8^{\circ} \mathrm{C}\right)$ and the floor $\left(18.1^{\circ} \mathrm{C}\right)$ of the semi-basement room are equal to those on the corresponding enclosures of the upper floor. 


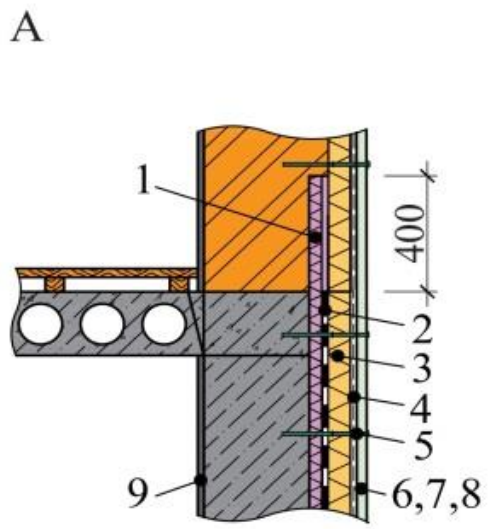

C
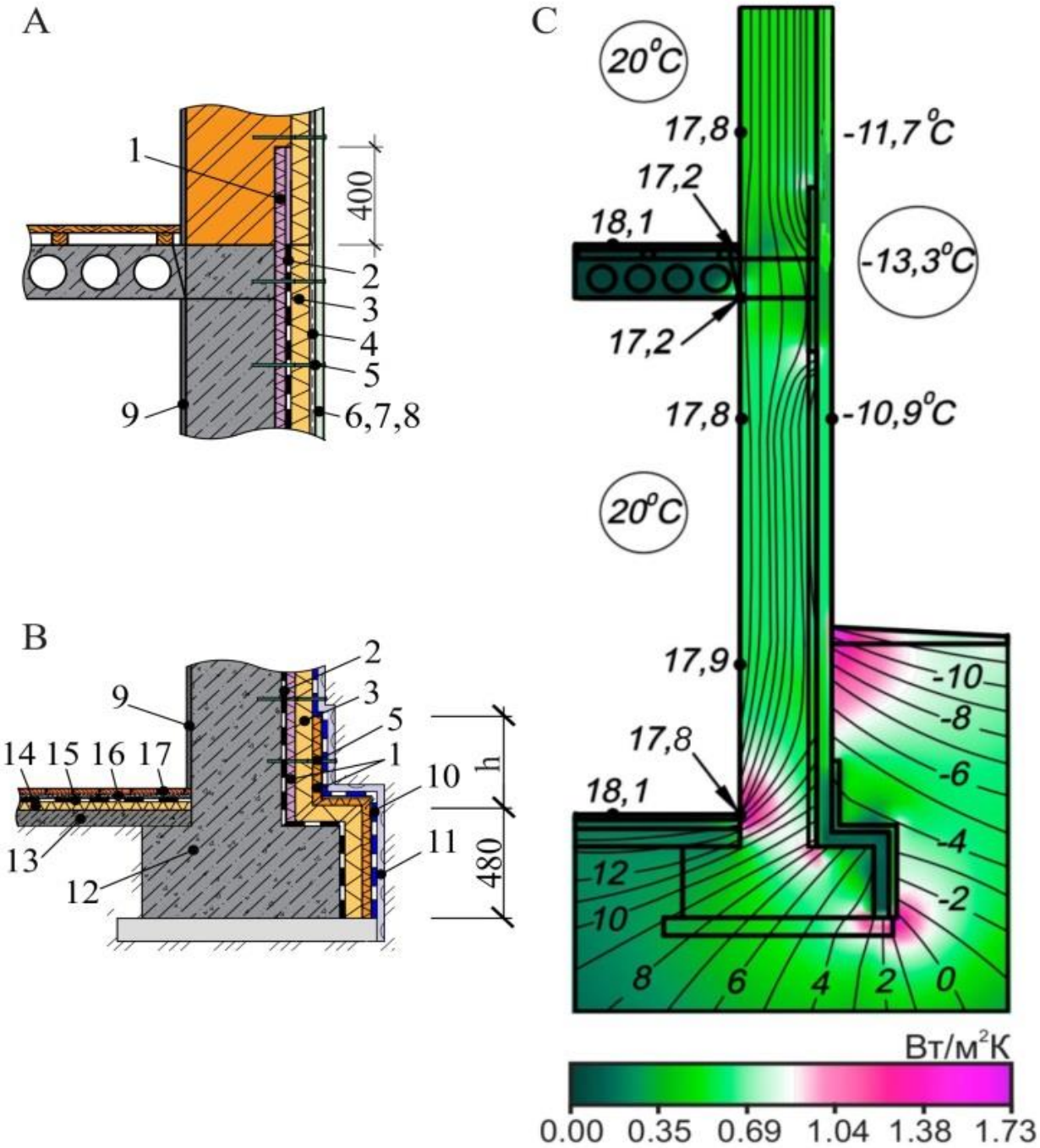

1 - additional thermal insulation layer; 2 - glue; 3 - main thermal insulation layer; 4 - glass mesh; 5 - dowel; 6, 7 and 8 - base, ground and decorative layers; 9 - plaster; 10 - two-layer waterproofing; 11 - protective membrane; 12 - foundation base; 13 - concrete screed; 14 and 15 - thermal insulation and waterproofing layers; 16 - cement-sand screed; 17 - parquet floor

Figure 8. The recommended constructive solutions: (A) the coupling between the floor and external wall; (B) the coupling between the semi-basement floor and monolithic foundation wall. (C) isotherms and heat flux densities.

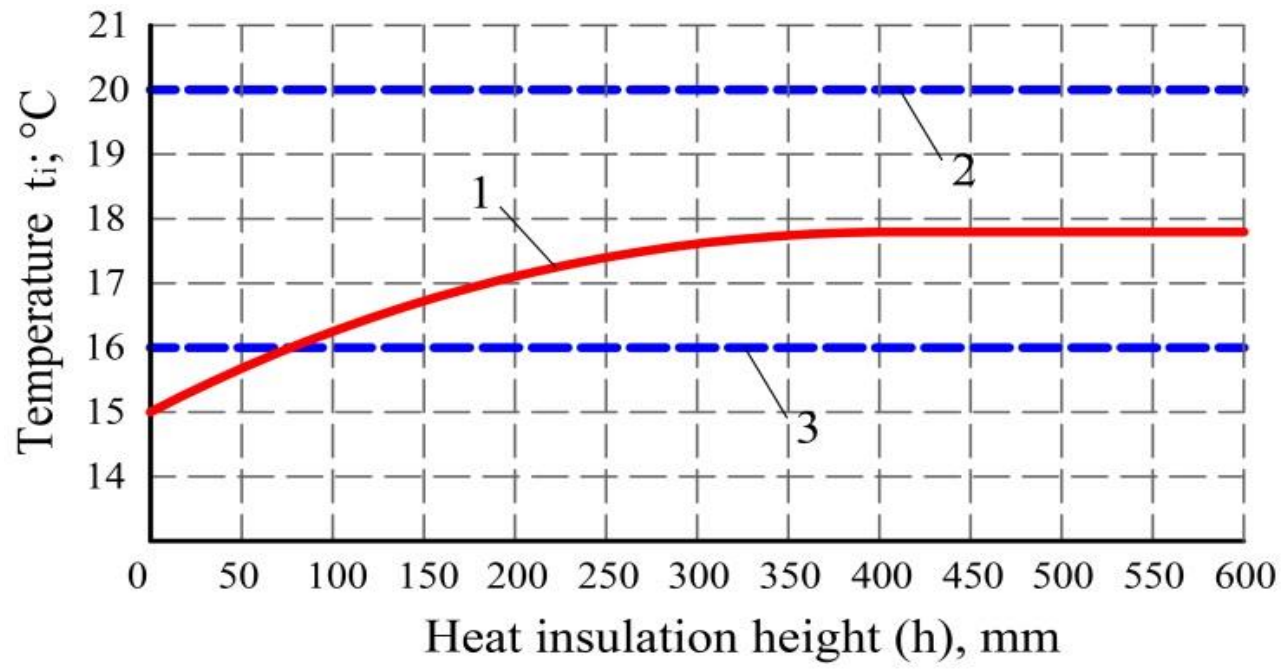

Figure 9. Graph of temperature $t_{i}$ versus the additional thermal insulation layer width - (1); the standard room air temperature - (2); the permissible temperature on the inner surface of the external wall - (3) 


\subsection{Key Results for Dissemination}

Based on the research results presented in Section 3.2, a scientifically substantiated and practically important conclusion was obtained: By meaning multivariate numerical studies, it was created such microclimate conditions in the semi-basement that are almost the same as the microclimate conditions in the usual room of the upper floor. Therefore, the proposed constructive solutions allow placing the main rooms of the house, for example, bedrooms and living rooms, in a semi-basement space. An important result of the study will be also that these rooms will provide more stable daily, seasonal and year-round thermal comfort conditions.

It should be noted that the proposed solutions were taken into consideration of the convenient technology for applying layers of glue, thermal insulation, waterproofing, and protective membrane.

Naturally, it is possible to use other options for technologies and materials with acceptable properties and dimensions.

The Figure 9 shows a graph of the dependence of the temperature $t_{i}$ on the upper width $h$ of the additional layer of thermal insulation (see Figure 8B).

As can be seen from Table 2, with a decrease in the thermal conductivity coefficient $\lambda$ of the considered types of soil, the temperatures on the considered surfaces increase.

This means that at the same time the intensity of the heat flow of the room towards the sides of the soil layer decreases. Taking into account such a theoretical basis for heat transfer processes, we planned and carried out research for the most unfavorable conditions of thermal interaction of semi-basements with adjacent soil, namely with sand (see the last line of the Table 2).

With an increase in $\mathrm{h}$ to $400 \mathrm{~mm}$ and higher, the temperature at the corner of the floor reaches a maximum value of $17.8^{\circ} \mathrm{C}$. It is equal to the temperature on the main surfaces of the concrete and brick walls. This means that under conditions when $\mathrm{h}=400 \mathrm{~mm}$, the negative effect of the thermal bridge in the zone of the foundation base is excluded.

On the basis of numerical investigations, we have established that the proposed constructive solutions (see Figure 8) can be successfully used with other types of building foundation soil.

The results of these investigations are presented in Table 2.

In other words, with other types of soil - clay, loam, sandy loam and sand - the feasibility of the proposed design solutions is higher, namely, the energy efficiency and microclimate levels in semi-basements become higher.

In addition, at such relatively high values of $t_{a}, t_{i}$ and $t_{s}$ the likelihood of moisture condensation and mold growth on vulnerable surfaces is significantly lower.

Table 3 shows the results of calculating heat losses through the concrete walls of the semi-basement for the reference heating period using the VALTEC program for 6 typical settlements in Kyrgyzstan and Tajikistan.

It has been established that the proposed constructive solution of the semi-basement wall allows reducing the heat consumption of semi-basement rooms by $16-20 \%$.

The savings in concrete for the semi-basement wall were saved by $5.22 \mathrm{~m}^{3}$, which is $10-12 \%$.

Table 2. Influence of soil properties on temperatures on the inner surface of the concrete wall, corner and floor of the semi-basement room

\begin{tabular}{|c|c|c|c|c|c|}
\hline \multirow[b]{2}{*}{ Soil types } & \multicolumn{2}{|c|}{ The soil characteristics } & \multicolumn{3}{|c|}{ Surface temperatures, ${ }^{\circ} \mathrm{C}$ (see Figure 5A) } \\
\hline & $\begin{array}{l}\text { Density, } \\
\rho, \mathrm{kg} / \mathrm{m}^{3} \\
\end{array}$ & $\begin{array}{c}\text { Coefficient of thermal } \\
\text { conductivity, } \lambda, \mathrm{W} / \mathrm{m} \cdot \mathrm{K}\end{array}$ & $\begin{array}{c}\text { On the concrete } \\
\text { wall, } t_{\mathbf{a}}\end{array}$ & $\begin{array}{c}\text { On the floor } \\
\text { corner, } t_{i}\end{array}$ & $\begin{array}{c}\text { On the floor, } \\
t_{s}\end{array}$ \\
\hline Clay & 1800 & 0.5 & 18.2 & 18.4 & 18.7 \\
\hline Loam & 1900 & 1.4 & 18.1 & 18.1 & 18.3 \\
\hline Sandy loam & 1800 & 1.8 & 18.0 & 18.0 & 18.2 \\
\hline Sand & 2200 & 2.3 & 17.9 & 17.8 & 18.1 \\
\hline
\end{tabular}

Table 3. Annual heat losses and energy-savings for heating the semi-basement space for typical settlements of Kyrgyzstan and Tajikistan

\begin{tabular}{|c|c|c|c|c|}
\hline \multirow{2}{*}{$\begin{array}{c}\text { Typical } \\
\text { settlements }\end{array}$} & \multirow{2}{*}{$\begin{array}{c}\text { Degree days, } \\
{ }^{\circ} \text { C·day }\end{array}$} & \multicolumn{4}{|c|}{$\begin{array}{c}\text { Annual heat losses and energy-savings for heating the semi-basement space, kWh/year } \\
\text { (see Figure 7A) }\end{array}$} & $\begin{array}{c}\text { Proposed option II } \\
\text { (see Figure 8C) }\end{array}$ & Energy-savings \\
\hline \multicolumn{5}{|c|}{ The Kyrgyz Republic } \\
\hline Bishkek & 2970 & 26076.7 & 21644.1 & 4432.6 \\
\hline Toktogul & 3008 & 26410.3 & 21921.0 & 4489.3 \\
\hline Naryn & 4992 & 28098.5 & 22954.3 & 5144.2 \\
\hline \multicolumn{7}{|c|}{ The Republic of Tajikistan } \\
\hline Dushanbe & 1584 & 24031.3 & 20158.7 & 3872.6 \\
\hline Khujand & 1984 & 25738.9 & 21102.0 & 4636.9 \\
\hline Khorog & 3370 & 25821.6 & 21483.0 & 4338.6 \\
\hline
\end{tabular}




\section{Discussions}

An analysis of the results of studies of the seismic resistance of buildings shows that many authors studied particular issues of the strength of a building and its individual enclosures. As in our research, the authors of work [16] point to the advisability of using numerical studies of the seismic resistance of brick buildings. The features of the destruction of building enclosures as a result of an earthquake showed that the structural units of the interface of the external enclosures with each other are the most vulnerable.

The article [17] considers the problem of ensuring the required seismic resistance of low-rise buildings by means of a frame. In our case, we studied the features of the seismic resistance of a building with a reinforced concrete monolithic frame. The article [18] presents the features of the behavior of the semi-basement wall, which arise because of various seismic pressure fluctuations of the adjacent soil. Based on the research, the coefficient of wall shift due to seismic effects was determined [19]. The work [20] studies the features of seismic displacement of reinforced concrete walls taking into account the coefficient of elasticity of structures of low-rise buildings.

The article [21] is devoted to the study of the linear and nonlinear seismic behavior of a building with various structures of a seismic-resistant frame.

It should be noted that theoretical and practical results that were obtained in the above-mentioned works do not contradict our results described in Section 3.1. The analysis of studies on the problem of increasing the energy efficiency of buildings showed that many authors mainly sought to solve particular problems related only to the thermal protection properties of the enclosing structures without considering buildings seismic resistance and microclimate.

In work [22], as in this article, it was noted that the heat losses of the basement of residential buildings occur more intensively through the walls than through the floor. At the same time, sanitary-hygienic conditions are often violated in the premises due to the formation of dampness on the walls. Such dampness not only reduces the thermal protection and load-bearing capacity of the wall structures, but will also lead to partial destruction even during weak earthquakes. This influence grows with the increasing of the wall material moisture [23], when the moisture content of the adjacent soil increases due to atmospheric precipitations, if reliable protection against them is not provided.

At low temperatures of basement enclosures, there is a risk of increasing of the humidity of the wall structure and the appearance of dampness on them [24, 25]. One of the reliable measures to reduce this risk and ensure the required level of thermal protection of external walls is their external thermal insulation [26].

As one of the results of our research, we proposed measures to prevent mold growth in wetter, colder corners of external enclosures. Based on the analysis of the temperature distribution inside of the enclosures using computer programs, it is possible to determine their required thermal protection capacity [27, 28].

The authors of the works $[29,30,31]$ used computer calculations of the heat flow through the enclosures to ensure their normative level of thermal protection.

As in the above-mentioned works, we also used software packages for research. The heat-shielding capacity of the basement walls was studied [27] taking into account the features of two-dimensional temperature fields in the soil mass adjacent to the foundation. In this article, we made decisions based on the analysis of the features of isotherms on the cross-sections of elements of external enclosures and in the mass of the adjacent soil.

As in the article [32], in our case, the thermal insulation of the basement base allowed to reduce the heat losses of the semi-basement rooms of the building. In work [33], calculations of heat losses through enclosures adjacent to the ground were carried out when using a warm floor. The article [34] examines the heat losses of basement rooms depending on the soil properties and the features of the thermal insulation of enclosures. In work [35], the thickness of the thermal insulation of the external walls was calculated taking into account the duration of the heating period.

Similar results of our investigations are presented in Table 3 for the considered building (see Figure 1) in typical cities of Kyrgyzstan and Tajikistan.

The authors of works [36,37] present the results of field investigations of external enclosures on the various building facades. They also note that there are increasing heat losses through separate areas of the facade, caused by the negative effect of thermal bridges.

The author of works $[2,3]$ obtained interesting results of field investigations of the building by contactless measurement of daily changes of the temperatures on the inner and outer surfaces of the external walls and windows. A significant decrease of temperatures of inner surfaces on the enclosures may cause indoor air moisture condensation during cold hours of the day.

These discussions confirm the correctness of the research tasks and the results of this article since they do not contradict the data of modern researchers.

\section{Conclusions}

1. The known theory and experience of energy-saving architecture allow establishing and solving multidisciplinary tasks for improving the structural and functional indicators of a building. It also allows ensuring sufficient insolation, passive solar heating, and occupant contact with environmental nature through appropriately developed semi-basement 
windows. An important problem of the full-fledged use of the semi-basement space of buildings is solved based on investigations of the mutual influence of seismic resistance, energy efficiency, and microclimate with ensuring room sanitary-hygienic conditions.

2. By means of numerical investigations, it was established that architectural and structural thermal bridges, which are in contact with the soil and outside air, reduce the thermal protection capacity of the building's thermal envelope. Visual isotherms and heat flux densities in the zone of such thermal bridges made it possible to determine and eliminate the causes of unacceptably low temperatures on the inner corners of external enclosures.

3. The expedient thickness and width of the additional layer of the thermal bridge zone thermal insulation in excess of the normative main layer of enclosure thermal insulation were established. The proposed graph dependence of the target temperature on the wall's inner corner from this width allows choosing an appropriate microclimate level.

4. A multilateral contribution to building improvement is derived from a single-family home example: comfortable microclimate conditions have been created in the semi-basement for placing main rooms; energy savings for heating this space is 16-20\%; saving of concrete for a monolithic frame and foundation is $10-12 \%$, ensuring higher than normative building seismic-resistance.

\section{Acknowledgements}

The authors would like to express their gratitude to the Public Foundation «Unison» in Bishkek, Kyrgyzstan, for an everlasting partnership in climate challenges and sponsorship support of this research.

\section{REFERENCES}

[1] E. Boronbaev, Energy-saving Architecture: Background, Theory and Practice in Kyrgyzstan in the e3s-conference Proceedings of 12th Nordic Symposium on Building Physics (NSB 2020), 6-9 September 2020, Tallinn, Estonia. E3S Web of Conferences, 172, 19010 (2020) DOI: https://doi.org/10.1051/e3sconf/202017219010

[2] E.K. Boronbaev. Field studies of daily temperature changes on the outer and inner surface of the external walls of the building, Industrial and Civil Construction, 2, 2011, pp. 57-58.

[3] E.K. Boronbaev. Field measurements of temperatures: the south faced window of the building as a source of heat and cold, Industrial and Civil Construction, 2, 2011, pp. 59-60.
[4] E.K. Boronbaev. Energy-saving architecture and thermal bridges, The herald of KSUCTA, Bishkek. 4, 2013, pp. 130-136.

[5] I. Bulakh, I. Merylova. Sustainable Hospital Architecture Potential of Underground Spaces, Civil Engineering and Architecture, 8(5), 2020, pp. 1127-1135. DOI: 10.13189/cea.2020.080539.

[6] A. Hamburg, T. Kalamees. The influence of heat loss from pipes in an unheated basement on the heating energy consumption of an entire typical apartment building in the e3s-conference Proceedings of 12th Nordic Symposium on Building Physics (NSB 2020), 6-9 September 2020, Tallinn, Estonia. E3S Web of Conferences 172, 12005 (2020) DOI: https://doi.org/10.1051/e3sconf/202017212005

[7] A. Nocente, S. Grynning. Thermal mass and the effects on heating and cooling demands-an experimental study of an exposed concrete floor, in the e3s-conference Proceedings of 12th Nordic Symposium on Building Physics (NSB 2020), Trondheim, Norway. E3S Web of Conferences, 172, 03004 (2020) DOI: https://doi.org/10.1051/e3sconf/20201 7203004

[8] A. Shandilya, M. Hauer, W. Sreicher, Optimization of thermal behavior and energy efficiency of a residential house using energy retrofitting in different climates, Civil Engineering and Architectures, 8(3), 2020, pp. 335-349. DOI: $10.13189 /$ cea.2020.080318

[9] S. Roaf, D. Crichton, F. Nicol, Adapting Buildings and Cities for Climate Change. A 21 st Century Survival Guide Second ed. - Oxford, UK/Burlington, USA: Elsevier, 2009, pp. 1-385.

[10] A. Abdykalykov, E. Boronbaev, U. Begaluev, K. Holmatov, N. Zhyrgalbaeva, Building wall corner structures, its microclimate and seismic resistance, in the e3s-conference Proceedings of 24th International Scientific Conference "Construction the Formation of Living Environment" (FORM-2021), April 22-24, 2021, Moscow, Russia. E3S Web of Conferences 263, 04051 (2021). DOI: https://doi.org/10.1051/e3sconf/202126304051

[11] A. Starakiewicz, P. Mia sik, J. Krason, L. Lichołai. Methods for Determining Mold Development and Condensation on the Surface of Building Barriers. Buildings, 10, 4, 2020, pp. 1-15. https://doi: 10.3390/buildings 100110004

[12] T.A. Belash, A.V. Kuznetsov. Energy efficient wall enclosing structures. IOP Conference Series: Materials Science and Engineering, 2018, pp. 1-8. DOI:10.1088/1757-899X/463/3/032052

[13] E.K. Boronbaev, K.N. Holmatov, Expedient coupling of the floor slab and external wall by required seismic resistance and energy efficiency of buildings, Science, new technologies and innovations, 2, 2020, pp. 11-16. DOI:10.26104/NNTIK.2019.45.557

[14] SP 20.13330.2011, Loads and impacts, Updated version of SNiP 2.01.07-85*, Moscow, 2011, pp. 1-122.

[15] SP 14.13330.2018, Construction in seismic areas, Updated edition of SNiP II-7-81*, Moscow, 2018, pp. 1-122.

[16] I. Tomic, F. Vanin, I. Bozulic, K. Beyer. Numerical simulation of unreinforced masonry building with timber 
diaphragms. Buildings, 11, 205, 2021, pp. 1-20. https://doi.org/10.3390/buildings11050205

[17] U. D. D. Liyanage, T. N. Perera, H. Maneetes. Seismic analysis of low and high-rise building frames incorporating metallic yielding dampers. Civil Engineering and Architectures, 6 (2), 2018, pp. 41-53. DOI: 10.13189/cea.2018.060201

[18] E. Amirzehni, M. Taiebat, W.D.L. Finn, R.H. DeVall. Seismic performance of deep basement walls, in the 6th international conference on earthquake geotechnical engineering, November 1-4, 2015, Christchurch, 2015, pp. 1-9. https://www.researcgate.net/publication/292146592

[19] E. Aydin, B. Ozturk, O.F. Kilinc, Seismic Response of Low-Rise Base Isolated Structures, The 15th International Conference, Lisboa, Portugal, 24-28 September, 2018, 24, pp. 19493-19503.

[20] J. Carillo, A. Rubiano. Displacement ductility for seismic design of RC walls for low-rise housing. Latin American Journal of Solids and Structures, 11, 2014, pp. 725-737. DOI: $10.1590 / \mathrm{S} 1679-78252014000400010$

[21] H. Baghaei, R. Razani. Comparative study of linear and nonlinear seismic behavior of non-isolated, base-isolated and top floor (TMD-type) isolated structural frames. Civil Engineering and Architectures, 7(1), 2019, pp. 5-16. DOI: 10.13189/cea.2019.070102

[22] C. Bruno, P.E. Grunau, Anchorage foundation insulation study, 2014, pp. 1-50.

[23] I. Skotnicova, L. Lausova, Temperatures and Heat Transfer Beneath a Ground Floor Slab, International Journal of Materials, 3, 2016, pp. 26-32.

[24] S.K. Asphaug, T. Kvande, B. Time, R.H. Peuhkuri, T. Kalamees, P. Johansson, U. Berardi, J. Lohne, Building and Environment. pp. 1-14 (2020), https://doi.org/10.1016/j.bui ldenv.2019.106572

[25] T. J. Kesik, M.C. Swinton, M.T. Bomberg, M.K. Kumaran, N. Normandin, W. Maref, Cost Effective Basement Wall Drainage Alternatives Employing Exterior Insulation Basement Systems (EIBS), The 8th Conference on Building Science \& Technology, Toronto, Ontario, 22-23 Feb., 2001, pp. 377-392.

[26] M.C. Swinton, M.T. Bomberg, M.K. Kumaran, N. Normandin, W. Maref, Performance of Thermal Insulation on the Exterior of Basement Walls, Construction Technology Update, 36, 1999, pp. 1-8.

[27] T.A. Kornilov, A.Ya. Nikifirov. Effectiveness Evaluation of Cellar Application with Controlled Temperature Mode in Low-Rise Buildings with Pile Foundations, IOP Conference Series: Materials Science and Engineering, 2021, pp. 1-9. https://DOI:10.1088/1757-899X/1079/6/062 011
[28] I. Ickiewicz, Soil freezing and the depth of spread foundations, in the e3s-conference Proceedings of 6th Conference SOLINA Sustainable Development, 13 August 2018, Solina, Poland. E3S Web of Conferences, 49, 00046 (2018), DOI: https://doi.org/10.1051/e3sconf/20184900046

[29] J. Hallik, T. Kalamees. A new method to estimate point thermal transmittance based on combined two-dimensional heat flow calculation, in the e3s-conference Proceedings of 12th Nordic Symposium on Building Physics (NSB 2020), 6-9 September 2020, Tallinn, Estonia. E3S Web of Conferences, 172, 80050 (2020), DOI: https://doi.org/10.1 051/e3sconf/202017208005

[30] T. Kalamees, S. Ilomets, M. Poldary, P. Kloseiko, U. Kallavus, M. Rosenberg, K. Oiger, Analysis of causes of the end of service life of a spray polyurethane foam and roof, in the e3s-conference Proceedings of 12th Nordic Symposium on Building Physics (NSB 2020), 6-9 September 2020, Tallinn, Estonia. E3S Web of Conferences, 172, 15002 (2020), DOI: https://doi.org/10.1051/e3sconf/2020172150 02

[31] A. Ficapal, I. Mutis. Framework for the Detection, Diagnosis, and evaluation pf thermal bridges using infrared thermography and unmanned aerial vehicles. Buildings, 9, 179, 2019, pp. 1-15. https://doi: 10.3390/buildings9080179

[32] B. Tudor, B. Andrian, Contributions to the Modeling of Conductive Heat Transfer Between the Foundation of a Building and Ground, The 8th International Conference on Industrial Power Engineering, Bacau, Romania, 14-15 Apr., 2011, pp. 25-30.

[33] M. Kratrti. Implementation of Two-Dimensional Foundation Model for Radiant Floors into Energy plus, SimBuild2004, IBPSA-USA National Conference Boulder, 4-6 August, 2004, pp. 1-12.

[34] S. Choi, M. Krarti, Effects of Layered Soil on Basement Heat Transfer, Thermal Envelopes VII / Thermal analysis of building systems - principles. 1998, pp. 553-560.

[35] C. Onan, S. Erdem, D.B. Ozkan, C. Analysis of Optimum Insulation Thickness for External Walls at Different Orientations Based on Real-Time Measurements, Thermal Science, 24, 3B, 2020, pp. 2035-2046. https://doi.org/10.2298/TSCI180710311

[36] A. Urzędowski, D. Wójcicka-Migasiuk, J. Styczeń. Analysis of Thermal Properties and Heat Loss in Construction and Isothermal Materials of Multilayer Building Walls, Advances in Science and Technology Research Journal, 11, 2, 2017, pp. 33-37. https://DOI:10.12913/22998624/69418

[37] P. Krause, A. Nowo'swiat, K Pawłowski. The Impact of Internal Insulation on Heat Transport Through the Wall: Case Study, Applied. Science, 10, 21, 2020, pp. 1-18. https://DOI:10.3390/app10217484 